Review

\title{
Exploring the Connections between Backrooms, Inventory Record Inaccuracies, and Waste
}

\author{
Madison J. Bixler* and Dorothée Honhon
}

Citation: Bixler, M.J.; Honhon, D. Exploring the Connections between Backrooms, Inventory Record Inaccuracies, and Waste. Sustainability 2021, 13, 9490. https://doi.org/ $10.3390 /$ su13179490

Academic Editor: Elena Cristina Rada

Received: 21 July 2021

Accepted: 19 August 2021

Published: 24 August 2021

Publisher's Note: MDPI stays neutral with regard to jurisdictional claims in published maps and institutional affiliations.

Copyright: (C) 2021 by the authors. Licensee MDPI, Basel, Switzerland. This article is an open access article distributed under the terms and conditions of the Creative Commons Attribution (CC BY) license (https:/ / creativecommons.org/licenses/by/ $4.0 /)$.
Naveen Jindal School of Management, The University of Texas at Dallas, Richardson, TX 75080, USA; dorothee.honhon@utdallas.edu

* Correspondence: mjb140030@utdallas.edu

\begin{abstract}
This paper explores the impact of retail store backrooms on inventory record inaccuracies (IRI) and waste. A trend in the retail industry is operating in the absence of a backroom. Benefits of operating without a backroom can include more employee presence on the sales floor, quicker replenishment (or the elimination of traditional backroom to shelf replenishment entirely), lower on-hand inventory, and the reduction of waste in the form of time, labor, cashflow, and product obsolescence. By conducting a literature review of the published literature on retail backrooms, this paper explores two additional unstated benefits to retailers operating without a backroom; specifically, the reduction of IRI and waste-an angle that has been previously understudied in the current academic literature. The objectives of this paper include defining a link between the existence of a backroom and waste/IRI, presenting an opportunity for future research in this area of study, and providing practical advice for corporations that wish to operate with or without a backroom.
\end{abstract}

Keywords: backroom; inventory record inaccuracy; waste; phantom stockout

\section{Introduction}

Supply chains continue to adapt to consumer demands for shorter lead times, lower costs, and higher product availability. To remain cost competitive, retailers seek to remove waste from their systems in the form of hidden processing costs, labor, and obsolescence or unsold products left over at the end of a selling season. In efforts to increase product availability, retailers attempt to provide better inventory data across their systems, as previous research explains that accurate inventory data reduces the chance of stockouts [1]. In a growing omnichannel environment, inventory data is also now frequently available to the consumer, motivating retailers to maintain correct records. While providing accurate inventory information to consumers grows more imperative in omnichannel fulfillment, extensive research has been carried out on the deleterious effects of inaccurate inventory data on retailers. Atali et al. [2] note that inventory record inaccuracies (IRI) trigger the bullwhip effect upstream, affecting replenishment and inventory management, impacting retailers as well as suppliers and distributors. The causes of these IRI can be system transaction errors, theft/shrinkage, and even misplaced or inaccessible inventory in backrooms [3]. This paper explores the impact that backrooms have on retailer IRI and waste. It should be noted that we take a Lean manufacturing definition of waste, by including not only obsolete/expired products, but also any non-value-added process steps. We define IRI as a divergence of "recorded quantities" in an inventory management system from the "actual quantities" on hand [1].

\subsection{Literary Contribution}

There has been limited research on the impact of a retailer eliminating the backroom, though a modern approach that we will refer to as "shelf-ready fulfillment", also referred to as "store-friendly delivery" [4], has emerged in the industry over the course of the last decade. Profitable, well known retailers such as Walmart, Target, and Whole Foods either 
operate with limited backroom space, or without a backroom altogether [5,6]. Walmart even implemented a "Top Stock" program in which they moved backroom inventory to the top shelf of their sales floor [7].

In a shelf-ready model, rather than having distributors deliver palletized products to the retail store (requiring the storage of overflow inventory in a backroom), distributors deliver case packs that can be carted directly from the truck to the retail shelf (Figure 1). These case packs are delivered at a specific cadence, or during each pre-defined replenishment cycle. While academic research on this shelf-ready (no backroom) model is limited, Corsten and Gruen [4] briefly explain the idea that stores without backrooms match store replenishment with shelf replenishment, resulting in replenishment processes that are more closely coordinated with demand. Trautrims et al. [8] note an occurrence within the past two decades in which the rise of omnichannel and e-tailing resulted in more congested backrooms for grocery retailers, causing a higher probability of out-of-stock Stock Keeping Units (SKUs) [8]. The present paper reviews the literature on backrooms and brings a novel connection to this research by defining a link between the existence of a retail backroom and the presence of IRI and waste in the retailer's operations. Additionally, we suggest an opportunity for future research on this link.

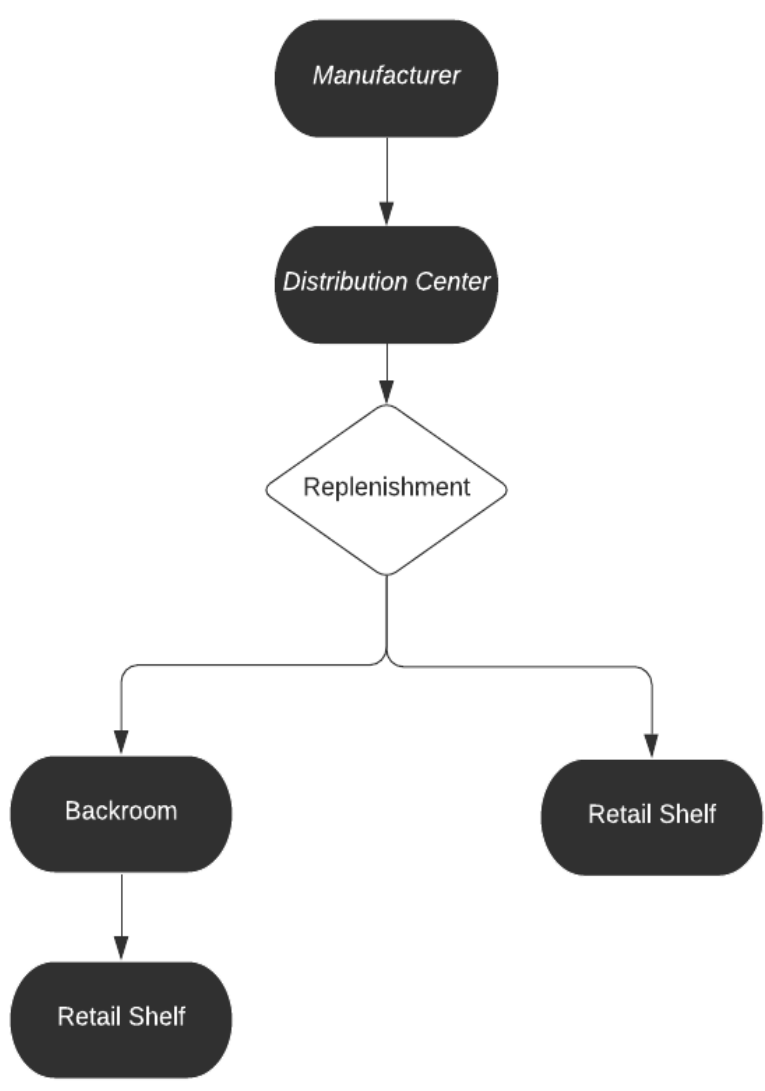

Traditional Fulfillment Model

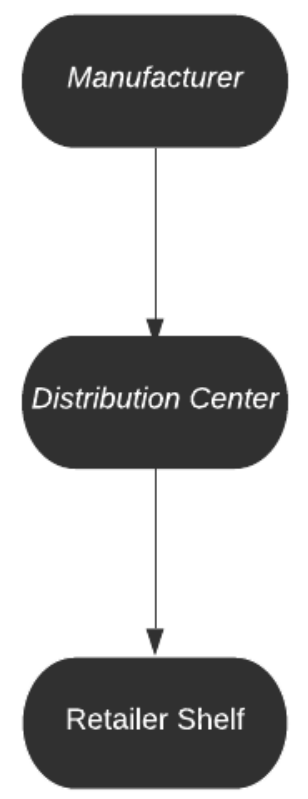

Shelf-Ready Fulfillment Model

Figure 1. Comparison of fulfillment channels with and without backroom existence.

\subsection{Research Question}

We ask the question, "what impact does the existence of a retail backroom have on IRI and waste?" Given that major retail chains in the Unites States have experimented with reducing backroom square footage, or eliminating their backrooms altogether, it is necessary to explore the impact of operating without a backroom. With the significant amount of academic studies surrounding IRI, we further extend the question to include 
the link between a backroom and IRI. We propose that there are several factors that backrooms introduce to a retail environment that increase the risk of IRI for a retailer and, simultaneously, increase waste within the operation of the retailer. This paper is broken down into sections based on these influencing risk factors, and includes published academic studies (both theoretical and empirical) as supporting evidence.

\subsection{Method}

The reviewed research spans over 20 years, beginning with some fundamental ideas on IRI and the backroom effect, and progresses to further developed and supported theories on these topics. Our review incorporates approximately 29 academic papers, authored by experts in various fields of research, including inventory accuracy, phantom inventory/stockouts, backroom operations, handling, and retail packaging. We also review five non-academic, industry related sources, and one book. These fundamental ideas serve as a strong foundation for this paper. The reviewed papers were selected based on discussions with academic experts on the subject of backroom and IRI, cross-referencing from earlier research, keyword queries (primarily "backroom," "waste," "Inventory Record Inaccuracy"), and cross-examination between the published literature from a variety of industry related journals, including Journal of Business Logistics, International Journal of Retail and \& Distribution Management, International Journal of Physical Distribution \& Logistics Management, and OR Spectrum. Databases used included EBSCO and Business Source Complete. Conclusions drawn from each piece of literature were synthesized into a cohesive argument for the existence of a link between backrooms, waste, and IRI.

\section{Backrooms Cause Ineffective Replenishment and Poor Store Execution}

In this section, we discuss how ineffective shelf replenishment can result from the existence of a backroom and how ineffective store execution can cause IRI. Backrooms are often treated as "graveyards" for misplaced or forgotten products. Given that most retail backrooms are 15-20\% of a retailer's store area [9] and are often home to many SKUs, there is a significant propensity for losing or misplacing products. Replenishing stock from backrooms can lead to putting all the items in the backroom, as opposed to stocking some on shelves, forgetting to replenish the sales floor, or failing to do so in a timely fashion [10]. It is important to note that most backrooms do not have assigned locations for items, and generally suffer from a lack of automation, often due to budget constraints [9]. It is apparent, in the related research, that inefficient backroom-to-shelf replenishment drastically lowers retailer performance [11,12].

Misplaced products in the backroom can result in incorrect shelf stocking, contributing to IRI or "phantom stockouts" (an issue that we discuss in a later section). For instance, after a case of products arrives at a store from the distributor, the products can be misplaced or lost [10], given the size and often unorganized nature of backrooms. If an employee later records or updates the inventory in the system and fails to record the misplaced items, IRI will occur and, as a result, the shelves may not be replenished appropriately. Employees may even perform a cycle count incorrectly if the inventory is hidden in the backroom, further complicating inventory discrepancies. From this example, we can see that the existence of a backroom may result in poor replenishment processes that cause IRI.

Corsten and Gruen [4], and Raman [10] point out that many inventory systems do not delineate between backroom location stock and shelf stock, meaning the inventory in backrooms is not well tracked, thus making them more susceptible to IRI. Few employees have time to count backroom inventory and compare on-hand inventory to system inventory, as backrooms are not prioritized when customers require attention on the sales floor. Because overflow goods are randomly assigned locations [4], and most inventory systems in retail stores do not specify where items are located, employees spend extra time looking for missing items, or may only replenish items that can be found easily. Corsten and Gruen [4] state that in $25 \%$ of their studied cases, inadequate shelf replenishments caused out of stock situations, when a product was somewhere in store (for instance, the backroom), but not 
on shelves. Rekik et al. [11] support this, observing that shelving errors cause misplaced products in a store and contribute to out of stock situations. Furthermore, Turgut et al. [13] remind us that shelf replenishment from backrooms likely does not occur until a shelf is already stocked out. Kang and Gershwin [3] note this as well, adding that long periods of time may pass before a store employee notices an empty shelf. With this said, misplaced and forgotten items can also affect a company's bottom line, as these products will likely not be available for purchase due to the inability to find the misplaced item.

Waller et al. [12] note that, $10 \%$ of the time, employees cannot find an item in the backroom, causing "less reliable" replenishment. In contrast, shelf-ready fulfillment eliminates the need to replenish from the backroom, and thus eliminates manual, less effective replenishments, as all items are immediately stocked on the sales floor. In shelf-ready replenishment, small quantities of overflow items (if any exist) are often placed on the top shelves of the sales floor, where they are still within sight of customers and are purchasable from the top shelf. In contrast, to replenish a shelf when the inventory is stored in a backroom, an employee must first realize a shelf is stocked out, have time to replenish an item, and then find the product in the backroom [12]. Eroglu et al. [14] echo that the replenishment from backroom to shelf is "unreliable" and "ineffective." Turgut et al. [13] and Eroglu et al. [15] also explain that "operational complexity" increases with the presence of backroom inventory, implying that larger amounts of inventory lead to IRI.

It is known that stores with overflow inventory will often use a backroom. When inventory is stored in more than one place (i.e., store shelf and the backroom), it requires the monitoring of multiple locations for inventory counts. Corsten and Gruen [4] mention that this can be one of the largest drivers of IRI. Ton and Raman [16], Raman [10], and DeHoratius and Raman [1] also prove that the more inventory there is in a store, the more errors there are in shelf replenishment, which, as we have seen, cause errors in inventory record. Put simply, more inventory is more difficult to count and keep track of. High inventory levels in backrooms are made worse when the many different SKUs are misplaced, as employees cannot keep track of what is missing from the sales floor, leading to further poor store execution and the inability to maintain the correct inventory counts in the systems.

In hypermarkets specifically, larger backrooms (meaning more space for inventory to be stored) contribute to more out of stock products, causing IRI and inaccurate distribution information [17]. Raman [10] supports this, explaining that store layout, including "design, size, and number of backrooms," can affect store operations.

In summation of this section, we observe that inventory in backrooms leads to poor store operations and many replenishment errors, such as product misplacement, out of stock products, forgetting to replenish the sales floor, etc. Such errors cause inventory system discrepancies, as records cannot be kept accurate when products are missing or misplaced. Therefore, backrooms are shown to be a quiet catalyst of IRI.

\section{Backrooms Can Cause Many Types of Waste}

We mentioned the various types of waste that may occur from the existence of a backroom. As a reminder, we define waste as any obsolete or expired products, as well as non-value-added costs or processes, such as unnecessary processing costs, labor (including unnecessary motion) and holding costs.

Backrooms may cause obsolescence or expired products for multiple reasons. Often, store managers, or those responsible for reordering products, are motivated to order larger quantities of product for the benefit of lower fixed ordering costs. This motivation may also be justified with the existence of a backroom, simply because the store has a location to store the extra products. Larger orders may be stored in larger cases or pallets. Wen et al. [18] explain that when larger cases, or more products, arrive at a store, the quantity often exceeds the amount of store shelf space and must be stored in the backroom. This increases the handling costs significantly, as more products must be put away and eventually replenished. We discuss the impact of case pack size on backrooms in a later 
section. Wen et al. [18] also note that the larger the economic order quantity or "EOQ," (well explained by Andriolo et al. [19]) of a replenishment order, the greater the inventory holding cost will be. This results from the EOQ model's attempt to balance fixed ordering costs with inventory holding costs. As a result of ordering more inventory to gain a quantity discount, the probability that the product will go unused increases. Corporate retail chains may discontinue a product or remove a product line, which could render the extra units in the backroom obsolete, giving the store insufficient time to sell the extra amounts of the old product. This idea is similar to Akkas' [20] work, who argues that retailers' practice to "fill the hole" of retail shelves leads to increased product expiration. Significant research has been carried out on optimal inventory levels and replenishment practices to provide retailers with a template for reordering products. In two separate papers, Wang et al. describe a heuristic approach to minimizing holding costs by adjusting the levels of independent variables, such as order quantity, reorder point, safety stock, and review period [21,22]. Wang et al. [21] note that the inventory quantity received is often greater than the storage location allocated for it, explaining an exacerbated issue that results in spoiled or expired products if there is a dedicated storage location for the products to be placed upon arrival. Their results reinforce our idea that backrooms encourage waste, and result in "increased costs," as Wang et al. state [21]. Both studies provide a practical, computational model for minimizing waste that is useful for inventory management. Tai et al. [23] provide another optimal inventory policy, that accounts for over-storage amounts within a replenishment cycle. In their model, they define overstock costs as higher holding costs - a reminder that excessive inventory in an additional storage space (backroom, in our case) contributes to higher costs. Jeenanunta et al. [24] also provide a simulation-based optimization model to help identify the optimal order-up-to level, considering a replenishment lead time that is longer than the review period, that could be used to minimize a retailer's overstock.

While the above example refers mainly to non-perishable products, Verghese et al. [25] explain a similar concept in the grocery industry. "Retail-ready packaging" is a concept in which food specifically is delivered in "ready to sell" packages, from the grower to the retail store, in efforts to reduce product damage and waste from overhandling [25]. In the context of the retail store itself, overhandling refers to the extraneous transport of products from the backroom to the sales floor, and vice versa. Verghese et al. [25] state that retailers report increased sales, and thus, less product waste from this model, due to the higher visibility of the products put directly on the store shelf. This is supported by Kang and Gershwin's [3] idea that products generate more revenue on the sales floor, rather than in the backroom. Increased sales drive faster replenishment, reducing the potential for obsolescence. It should be noted that, while Verghese et al. [25] focus on packaging, the just-in-time model they explain still supports our idea that bypassing the backroom (whether in effort to reduce handling damage or for another reason) minimizes the physical waste of products. The authors state that the main reasons for food waste in the retail phase of the supply chain include excess stock (which can be caused by a large replenishment quantity, motivated by the existence of a backroom), poor stock rotation (which can occur from the almost certain delays in backroom-to-shelf replenishment [13]), and the excessive handling of delicate produce (unnecessary handling required to move products from a backroom to the shelf). Corsten and Gruen [4] also mention this retail packaging strategy, and recommend it to reduce damage and handling costs. They also add that store friendly delivery describes methods to load pallets and products on a truck in groups that reflect the store layout, meaning that they can be offloaded and taken directly to their shelves [4] (p. 34). Additionally, we believe there may be an opportunity in exploring the link between a just-in-time distribution model that bypasses a backroom, and food packaging material and shelf life, as discussed by Spreafico and Russo [26].

The existence of a backroom can also cause extra costs, such as information processing costs that would otherwise not be required, as well as additional holding and labor costs. We consider this to be waste, as the cashflow needed to support backroom-to-shelf 
operations could be removed, to result in a more streamlined replenishment process. Van Zelst [27] states that, within a retail supply chain, over "75\% of handling time [ . . ] occurs in store" [27] (pp. 620-621). In-store handling is also the most costly operational expense in retail chains, accounting for over $38 \%$ of all costs in the chain [27]. Information processing costs involve the extra, cognizant effort of an employee to notice an out of stock product on the sales floor, and the time required to replenish the item. Information processing costs are an additional expense of holding inventory on shelves and in backrooms, as the employee must monitor (and replenish) the inventory in both locations [14]. This is classified as waste, but also can contribute to IRI. Raman [10] explains that misplaced SKUs cause additional labor and carrying costs, as extra effort and time is spent searching for the misplaced items. In the previous section, we explained how backrooms may cause such misplaced SKUs. Xue et al. [28] remind us that there is often a difference between the cost of carrying an item (or case) in a backroom storage area and carrying the same item on the sales floor, where it can be a source of revenue simply by being in the sight of customers. Xue et al. [28] note that there are "potentially considerable" cost implications of these differences. In 2017, Walmart, realizing the impact of housing extra units on the sales floor, developed their "Top Stock" testing program in several stores, moving backroom inventory to the top shelf of their sales floor [7]. Besides creating more sales and therefore more revenue, Walmart believes that moving inventory out of the backroom leads to better inventory visibility, more space for ecommerce and omnichannel fulfillment, and better customer service [29]. Walmart cites that, after implementing the program, they were able to drastically reduce the amount of temporary inventory trailer rentals [29].

We acknowledge that having a backroom may allow, or encourage, retailers to order more products than needed to achieve economies of scale in purchasing, simply because they have the space to store it. However, this can lead to too much inventory on hand [16], and potential obsolescence (waste) from having too much of a product. Additionally, having a backroom causes waste in the form of handling and processing costs, as more labor and manual shelf monitoring is required by employees.

\section{High Inventory Causes Phantom Stockouts and Errors}

Until this point, we have seen that high inventory causes replenishment errors, as discussed previously. This inventory can accumulate per the existence of a backroom, as having more space to house inventory, as well as the quantity discounts offered by suppliers, incentivizes managers to order more products. In addition to the replenishment errors and the additional costs of handling that come from excess inventory, holding additional inventory in backrooms can lead to "phantom stockouts" or "phantom products." This section will examine phantom stockouts and explain how a backroom may facilitate them, subsequently contributing to IRI.

Phantom stockouts are defined as "stockouts" that result from inventory that is out of customer view, perhaps in a backroom, and therefore unpurchasable [2]. Ton and Raman [16] define these similarly, as "phantom products," caused by replenishment and shelving errors, where a product is present in the store, but not in the right location for customers to purchase. These phantom stockouts frequently occur when employees do not move products from the backroom to the shelf [30]. It is also important to note the difference between "phantom inventory" and phantom stockouts. Phantom inventory occurs as a result of IRI, in which an inventory system shows that a product is available, but the shelf is empty [4]. However, this paper will focus on phantom stockouts, where product is on hand, but missing from the sales floor.

It is possible for phantom stockouts to cause IRI. Similar to our example in the first section, when a product is missing from the sales floor or stored in the backroom out of customer view, the inventory may go uncounted or may not be adjusted in the inventory system. This is often due to employee error, such as forgetting about, or misplacing, the excess inventory. Eroglu et al. [14], who refer to phantom stockouts as "shelf stockouts," specify that phantom stockouts normally occur when inventory is stored in two locations: 
the backroom and the sales shelf. They add that the nature of backroom-to-shelf replenishment, which we have already shown to be unreliable and operationally inefficient, increases the likelihood of phantom stockouts. The main consensus of Eroglu's [14] work and the related literature is that backrooms not only deter customer purchases due to hidden products stored in the backroom, but can also misinform retail inventory systems of what is truly on hand, creating IRI. In the modern retail environment, we see a similar trend of avoiding backrooms, as Walmart repositions inventory to top sales floor shelves to (a) minimize the locations in which inventory is held, and (b) gain sales advantages from housing excess inventory within customer sight [7]. Eroglu et al. [14] develop Corsten and Gruen's [4] work on the determent of having inventory in multiple locations, connecting this specifically to backrooms, as they define a positive correlation between the amount of inventory in backrooms and phantom stockouts.

To provide an example for this point, we mention Fisher and Raman's [31] work who, in their book, The New Science of Retailing, identify a phantom stockout trend in the Dutch grocer, Albert Heijn. They track customer purchases of a bread SKU against customer traffic, identifying a period of the day in which the bread SKU did not sell due to incorrect replenishment from the backroom [31] (p. 177). In contrast, had this retailer coordinated delivery, order quantities, and unloading to resemble a shelf-ready model, their incorrect, manual replenishment would have been avoided and they would likely have realized increased sales of bread. Fisher and Raman [31] additionally cite a Borders bookstore survey, in which inventory was recorded as present in store but could not be found on the shelves, attributing this to books becoming lost or misplaced in the backroom. They connect this example to IRI, explaining that the inventory system showed a quantity of product on hand, but the product was not on the sales floor and, therefore, unable to sell. Reorders were also not triggered because there were no sales, due to these frozen SKUs. Through this, we see the costly nature of backroom related phantom stockouts and their effect on store revenue.

We see that, by holding inventory in multiple locations (including the backroom), there is a higher probability of phantom stockouts, creating potential IRI in a retailer's inventory system. Because of the IRI that can come from phantom products hidden in backrooms, Fisher and Raman [31] encourage retailers to move to a just-in-time (JIT) system, in which the backroom is bypassed entirely [31] (p. 175). Retailers that have implemented this across some or all stores, such as Walmart, Target, Whole Foods, and the Belgian retailer Brantano, are able to more closely control inventory; in fact, Brantano receives deliveries each day [31], which greatly resembles the shelf-ready model.

\section{Backrooms May Lead to Theft and Damage, Increasing IRI}

Now that we have discussed some of the larger issues with backrooms that contribute to IRI and waste, we move to some commonly overlooked (although equally important) consequences of backrooms. This section will discuss the potential for damaged inventory and theft in the backroom and how this contributes to IRI. As we have discussed, IRI exist when on hand inventory deviates from the inventory that is recorded in the system $[1,10]$. DeHoratius and Raman [1] note that one of the largest causes of IRI is theft or shrinkage. Atali et al. [2] note that thefts or damages are particularly costly to a retailer, as they are permanent shrinkages, rather than temporary shrinkage, which could be simply misplacing an item and finding it later. Thefts and damages are often unreported causing the inventory to appear higher in the system than what is on hand [2] resulting in a "freezing" effect on replenishment $[4,30]$. Kang and Gershwin [3] also mention that, in addition to theft, unidentified "stock loss," such as damages and expiration, also create IRI.

We propose that backrooms facilitate more theft and damage, and therefore more IRI. Corsten and Gruen [4] remind us that backrooms, and their corresponding operations, are rarely prioritized by retailers. As we have discussed in previous sections, backrooms are home to misplaced items and ineffective operational procedures, where inventory is subject to overhandling [18]. We will define overhandling in this section as the unnecessary 
movement of products. Verghese et al. [25] use the grocery industry to explain how packaging has been created that reduces overhandling by warehouse and store employees, as extra handling can cause damage to produce and other vulnerable items. When a backroom is utilized, the inventory that arrives at the store is either stored in the backroom first and then used to later replenish store shelves, or put directly on the sales floor, with leftover inventory being carted back to (and stored) in the backroom (Figure 1). In either case, the utilization of a backroom lends itself to extraneous steps in either replenishment or storage efforts. Thus, during the receiving and restocking process of a traditional fulfillment model, many opportunities are created for items to be damaged and discarded off the record, contributing to IRI. In contrast, a shelf-ready model reduces such overhandling and IRI, by storing items directly on the store shelves (where the process ends) and items remain untouched until customer purchase.

Backrooms can be areas of high or low traffic, depending on customer needs and employee task assignment. If a backroom is empty because most employees are busy attending to customers on the sales floor, an opportune moment may arise for other employees to steal merchandise, unnoticed, from the backroom.

In conclusion, we see that the existence of a backroom causes more theft and product damage, as a result of overhandling and inattentiveness to the backroom. The existing research has proven that undetected theft and damage creates IRI within a retailer's system, eventually disrupting store replenishment.

\section{Case Pack Size Influences Backroom Storage and Causes IRI}

There is limited, but profound, existing literature regarding the size of the product case packs packaged at a distribution center (DC). The case pack size can largely influence a retailer's ability to execute a shelf-ready operational model. Should case packs arriving at a retailer's store be too large, overflow inventory must be stored somewhere in the store. This necessitates the existence of a backroom and, thus, causes ineffective replenishment, increasing phantom stockouts. Turgut et al. [13] state that frequently, replenishment orders from a DC misalign with a store shelf size, creating excess inventory to be held and resulting in additional carrying costs. Eroglu et al. [15] show that the misalignment of case packs and store shelf space is the cause of the "backroom effect," a phenomenon in which the amount of inventory held in the backroom is dependent on the reorder point and case pack/shelf alignment. Why does this misalignment occur so often? Wen et al. [18] explain that it is less expensive for a DC to replenish with cases, due to the cost of labor to unpack or break down cases into individual units. Rarely do we see DCs ship individual units. It is also a fact that retailer shelving specifications are decisions made at the corporate level, and that manufacturers often define case quantity to reach economies of scale or lower transit costs to the DC [13], with little regard for store considerations. To guide shelf sizing decisions, Eroglu et al. [32] recommend "the pack and a half rule," in which the shelf size should be $50 \%$ larger than the case pack quantity that arrives from the DC. The goal in this advice is to, eventually, reduce or eliminate the need for a backroom. Eroglu et al. [14] make a unique connection between case pack size and phantom stockouts, hypothesizing that smaller case pack quantities result in fewer phantom stockouts. They attribute this to the lack of inventory in the backroom and more frequent replenishments. As we have discussed previously, backrooms create phantom stockouts due to the opportunity for the inventory to be held off the shelf or sales floor.

Waller [12] has carried out extensive research on the impact of misaligned case pack sizes and shelf space. He proves that case pack quantity significantly affects a retailer's market share, showing that aligned cases and shelves result in reduced phantom stockouts and, therefore, more products purchased by consumers. If we refer to Fisher and Raman's example of Albert Heijn and the bread SKU [31], we can better understand how, given a steady level of customer traffic, a store will lose sales if the product is not in the right place at the right time. Rather than having phantom stockouts, which decrease sales due to missing inventory (often lost in the backroom), a store should make efforts to keep the 
inventory within customer sight to increase market share. Waller's [12] work, as well as other research on case pack quantities and shelf space, once again encourages a model without a backroom; that is, a shelf-ready distribution model.

\section{Discussion and Conclusions}

In this paper, we have:

- Established a positive relationship between waste and IRI;

- Explained that retailers that operate without a backroom are more likely to experience benefits such as reduced costs, reduced obsolescence and expiration, less IRI, and increased market share through additional sales;

- Examined how inefficient operations and replenishment, as well as theft, may occur when a backroom is used, and analyzed the impact of phantom stockouts caused by backrooms;

- Cautioned how backrooms may increase the amount of expired or obsolete SKUs, and have explained how case pack size contributes to additional backroom inventory;

- Provided a pragmatic case for corporations to operate without using a backroom.

It is important to note that our paper provides an academic, ideal case for the elimination of a backroom in the retail environment. While we show the benefits of operating without a backroom and mention several retailers that have successfully enacted this practice, it should be recognized that not all retailers may find it beneficial to eliminate a backroom, either due to the size of the retailer, or simply due to the inability to implement such a lean method of fulfillment. While Fisher and Raman [31] note that it may be challenging for retailers to fully eliminate a backroom, we have noticed that, in the past decade, more retailers are attempting it. Bond [33] notes that "companies are recognizing the need to marry the interests of stores and distribution centers," as many retailers desire to remain competitive by implementing a shelf-ready fulfillment model. Our shelf-ready model requires significant coordination within the supply network, as distributor, retailer operations and inventory planning, as well as transportation must work closely to achieve a true just-in-time, shelf-ready model. Given the amount of coordination required, it should be noted that there are potential downfalls to stores operating without a backroom. For example, should a store incur any unwanted overflow inventory, they may struggle to find storage space for these items, especially if they lack room on the sales floor or have little shelf space. The store may experience similar issues if they need to hold additional inventory to support operations until the next truck arrives (buffer inventory) but have no place to store it. When operating without a backroom, retailers should consider a detailed planogram design to accommodate differing case pack quantities for different SKUs. This must be coordinated with the demand planning or inventory forecasting team to minimize the overflow of the inventory and should allow the retailer to better design their shelves for a shelf-ready model, in which the inventory is replenished more frequently. It is also important to note that there may be added costs incurred from the warehouse for the more frequent delivery of smaller loads [18]. One additional, although uncommon, risk of operating with any lean or JIT model is the potential for a delivery truck to be late or delayed, which may disrupt sales, depending on how much inventory a retailer has left. This has the potential to create a "bottleneck" in the operational process, meaning JIT models work best in situations of "stable systems" [34]. Table 1 provides a summary of our research and discussion. 
Table 1. Consequences of operating without a backroom in a retail environment.

\begin{tabular}{ll}
\hline \multicolumn{1}{c}{ Benefits } & \multicolumn{1}{c}{ Operation in Absence of Backroom } \\
\hline More inventory on sales floor results in higher sales per sq. ft. & Difficulty storing any overflow inventory/lack of buffer stock \\
\hline $\begin{array}{l}\text { Reduced waste (obsolescence/labor/handling costs) and lower } \\
\text { on-hand store inventory }\end{array}$ & $\begin{array}{l}\text { Potential added costs to warehouse due to smaller quantities } \\
\text { delivered more often }\end{array}$ \\
\hline Fewer phantom stockouts & $\begin{array}{l}\text { Potential lost sales if delivery truck is late or delayed on a given } \\
\text { day }\end{array}$ \\
\hline $\begin{array}{l}\text { Less inventory record inaccuracy and more accurate demand } \\
\text { forecasts }\end{array}$ & $\begin{array}{l}\text { Requires detailed planogram design and inventory planning } \\
\text { coordination }\end{array}$ \\
\hline Reduced theft and shrinkage & \\
\hline More streamlined, JIT replenishment & \\
\hline More employee presence on sales floor/better customer service & \\
\hline
\end{tabular}

\section{Future Research}

One could further this research in several ways. Perhaps the most obvious would be to conduct an empirical study with industry partners. To do so, one could use either simulation or industry data, comparing IRI levels and obsolescence rates in a store operating with a backroom and one without a backroom, or for the same store, before and after switching from operating with a backroom to implementing a shelf-ready fulfilment policy. In grocery retail stores specifically, the average shelf life (or "freshness") of products on the shelves could be compared with and without a backroom, alongside measures of discarded, expired products to determine the level of waste. To do so, such waste data measurements must exist.

Propositions for operating with smaller or leaner backrooms could also be made for retailers that may be hesitant to fully eliminate backroom options (such as sales floor storage), similar to Walmart's example of Top-Stock. To make such a suggestion, one would first need to analyze the delivery frequency of products arriving from the distribution center and examine the amount of potential on-floor storage available at the retailer's location.

There are, of course, limitations to said studies, including the possible lack of concise data from the retailer or distributor, and the inability to properly compare retailers with and without a backroom (due to operational differences, the number of employees, or square footage differences), and over time, before and after the implementation of the shelf-ready fulfillment model (due to other temporal differences and the learning curve effect). Perhaps the biggest challenge to eliminating a backroom or implementing a shelf-ready model, is the delivery coordination of the inventory from the distribution center. Matching these deliveries to store sales requires accurate sales data and a sufficient data exchange channel between the distributor and the retail store. Such a model does not take into consideration demand fluctuation, but some retailers may be able to share real time data with suppliers.

As mentioned in Section 3, there may also be a significant opportunity to explore the relationship between packaging (material, method, and processes) and backrooms or just-in-time models. In a study on perishable product packaging, Spreafico and Russo explain the variety of food packaging materials, each providing a different level of shelf life [26]. Operating without a backroom could lead to longer shelf life and reduced waste, and grocery retailers could experience benefits from reduced or different packaging requirements. The same authors also provide a framework for developing new ecofriendly processes; the TRIZ-based guidelines they proposed could be followed to eliminate or reduce the backroom of a retailer, with the aim of reducing waste. This research brings awareness to the environmental consequences of design changes throughout product life cycle [35]. 
While the total elimination of a backroom may not be possible for all retailers, this paper suggests that minor modifications, such as the reduction of the size of the backroom, storing excess inventory on the sales floor, or designing shelf-ready packaging, can provide helpful returns and added sales, while reducing waste and IRI.

Author Contributions: Conceptualization, M.J.B.; writing—original draft preparation, M.J.B.; writingreview and editing, D.H.; supervision, D.H. All authors have read and agreed to the published version of the manuscript.

Funding: This research received no external funding.

Institutional Review Board Statement: Not applicable.

Informed Consent Statement: Not applicable.

Data Availability Statement: Not applicable.

Conflicts of Interest: The authors declare no conflict of interest.

\section{References}

1. DeHoratius, N.; Raman, A. Inventory record inaccuracy: An empirical analysis. Manag. Sci. 2008, 54, 627-641. [CrossRef]

2. Atali, A.; Lee, H.L.; Özer, Ö. If the Inventory Manager Knew: Value of Visibility and RFID under Imperfect Inventory Information; Working Paper; Stanford University: San Francisco, CA, USA, 2009.

3. Kang, Y.; Gershwin, S. Information inaccuracy in inventory systems: Stock loss and stockout. IIE Trans. 2005, 37, 843-859. [CrossRef]

4. Corsten, D.; Gruen, T. A Comprehensive Guide to Retail Out-Of-Stock Reduction in the Fast-Moving Consumer Goods Industry. Available online: https://www.nacds.org/wp-content/uploads/2017/02/Retail-Out-of-Stock-Reduction.pdf (accessed on 22 October 2020).

5. Cosgrove, E. Target Credits New Tech with Lowering Backroom Inventory. Available online: https://www.supplychaindive. com/news/target-new-tech-will-finetune-inventory/567799/ (accessed on 6 October 2020).

6. Wells, J. Is Order-to-Shelf Technology the Future of Retail Distribution? Available online: https:/ /www.grocerydive.com/news / grocery--is-order-to-shelf-technology-the-future-of-retail-distribution/535376/ (accessed on 11 August 2021).

7. O'Shea, D. Walmart Gives Backroom Inventory Top-Shelf Treatment. Available online: https://www.retaildive.com/news/ walmart-gives-back-room-inventory-top-shelf-treatment/503029/ (accessed on 16 October 2020).

8. Trautrims, A.; Grant, D.; Fernie, J.; Harrison, T. Optimizing on-shelf availability for customer service and profit. J. Bus. Logist. 2009, 30, 231-247. [CrossRef]

9. Pires, M.; Pratas, J.; Liz, J.; Amorim, P. A framework for designing backroom areas in grocery stores. Int. J. Retail. Distrib. Manag. 2017, 45, 230-252. [CrossRef]

10. Raman, A.; DeHoratius, N.; Ton, Z. Execution: The missing link in retail operations. Calif. Manag. Rev. 2001, 43, 136-152. [CrossRef]

11. Rekik, Y.; Sahin, E.; Dallery, Y. Analysis of the impact of the RFID technology on reducing product misplacement errors at retail stores. Int. J. Prod. Econ. 2008, 112, 264-278. [CrossRef]

12. Waller, M.; Heintz Tangari, A.; Williams, B. Case pack quantity's effect on retail market share. Int. J. Phys. Distrib. Logist. Manag. 2008, 38, 436-451. [CrossRef]

13. Turgut, Ö.; Taube, F.; Minner, S. Data-driven retail inventory management with backroom effect. OR Spectr. 2018, 40, 945-968. [CrossRef]

14. Eroglu, C.; Williams, B.; Waller, M. Consumer-driven retail operations: The moderating effects of consumer demand and case pack quantity. Int. J. Phys. Distrib. Logist. Manag. 2011, 41, 420-434. [CrossRef]

15. Eroglu, C.; Williams, B.; Waller, M. The backroom effect in retail operations. Prod. Oper. Manag. 2013, 22, 915-923. [CrossRef]

16. Ton, Z.; Raman, A. The effect of product variety and inventory levels on retail store sales: A longitudinal study. Prod. Oper. Manag. 2010, 19, 546-560. [CrossRef]

17. Milićević, N.; Grubor, A. The effect of backroom size on retail product availability-Operational and technological solutions. Amfiteatru Econ. 2015, 17, 661-675.

18. Wen, N.; Graves, S.; Justin Ren, Z. Ship-pack optimization in a two-echelon distribution system. Eur. J. Oper. Res. 2012, 220, 777-785. [CrossRef]

19. Andriolo, A.; Battini, D.; Grubbstrom, R.; Persona, A.; Sgarbossa, F. A century of evolution from Harris's basic lot size model: Survey and research agenda. Int. J. Prod. Econ. 2014, 155, 16-38. [CrossRef]

20. Akkaş, A. Shelf space selection to control product expiration. Prod. Oper. Manag. 2019, 28, 2184-2201. [CrossRef]

21. Wang, C.; Dang, T.; Nguyen, N. A computational model for determining levels $\mathrm{n}$ of factors in inventory management using response surface methodology. Mathematics 2020, 8, 1210. [CrossRef] 
22. Wang, C.-N.; Nguyen, N.-A.-T.; Dang, T.-T. Solving order planning problem using a heuristic approach: The case in a building material distributor. Appl. Sci. 2020, 10, 8959. [CrossRef]

23. Tai, P.D.; Huyen, P.P.N.; Buddhakulsomsiri, J. A novel modeling approach for a capacitated (S,T) inventory system with backlog under stochastic discrete demand and lead time. Int. J. Ind. Eng. Comput. 2021, 12, 1-14. [CrossRef]

24. Jeenanunta, C.; Kongtarat, V.; Buddhakulsomsiri, J. A simulation-optimisation approach to determine optimal order-up-to level for inventory system with long lead time. Int. J. Logist. Syst. Manag. 2021, 38, 253-276. [CrossRef]

25. Verghese, K.; Lewis, H.; Lockrey, S.; Williams, H. Packaging's role in minimizing food loss and waste across the supply chain. Packag. Technol. Sci. 2015, 28, 603-6200. [CrossRef]

26. Spreafico, C.; Russo, D. A sustainable cheese packaging survey involving scientific papers and patents. J. Clean. Prod. 2021, 293, 126196. [CrossRef]

27. van Zelst, S.; van Donselaar, K.; van Woensel, T.; Broekmeulen, R.; Fransoo, J. Logistics drivers for shelf stacking in grocery retail stores: Potential for efficiency improvement. Int. J. Prod. Econ. 2009, 121, 620-632. [CrossRef]

28. Xue, W.; Caliskan Demirag, O.; Chen, F.; Yang, Y. Managing retail shelf and backroom inventories when demand depends on the shelf-stock level. Prod. Oper. Manag. 2017, 26, 1685-1704. [CrossRef]

29. Brooks, C. Why Smarter Inventory Means Better Customer Service. Available online: https:/ / corporate.walmart.com/newsroom/ business / 20170816/why-smarter-inventory-means-better-customer-service (accessed on 11 August 2021).

30. Chen, L. Fixing Phantom Stockouts: Optimal Data-Driven Shelf Inspection Policies; Working Paper; Duke University: Durham, NC, USA, 2021.

31. Fisher, M.; Raman, A. The New Science of Retailing; Harvard Business Press: Boston, MA, USA, 2010. ISBN 978-142-216-064-0.

32. Eroglu, C.; Williams, B.; Waller, M. Using the pack-and-a-half rule to eliminate backroom inventories in retail operations. J. Bus. Logist. 2018, 39, 164-181. [CrossRef]

33. Bond, J. Best Practices: Store-Ready Distribution Evolves. Available online: https://www.mmh.com/article/best_practices_ store_ready_distribution_evolves (accessed on 5 November 2020).

34. Shpak, S. Advantages \& Disadvantages of Lean Production. Available online: https://smallbusiness.chron.com/advantagesamp-disadvantages-lean-production-46696.html (accessed on 5 November 2020).

35. Russo, D.; Spreafico, C. TRIZ-based guidelines for eco-improvement. Sustainability 2020, 12, 3412. [CrossRef] 